\title{
Accelerated Passive Dosing of Hydrophobic Complex Mixtures-Controlling the Level and Composition in Aquatic Tests
}

Hammershøj, Rikke Høst; Birch, Heidi; Sjøholm, Karina Knudsmark; Mayer, Philipp

Published in:

Environmental Science and Technology

Link to article, DOI:

10.1021/acs.est.9b06062

Publication date:

2020

Document Version

Publisher's PDF, also known as Version of record

Link back to DTU Orbit

Citation (APA):

Hammershøj, R. H., Birch, H., Sjøholm, K. K., \& Mayer, P. (2020). Accelerated Passive Dosing of Hydrophobic Complex Mixtures-Controlling the Level and Composition in Aquatic Tests. Environmental Science and Technology, 54(8), 4974-4983. https://doi.org/10.1021/acs.est.9b06062

\section{General rights}

Copyright and moral rights for the publications made accessible in the public portal are retained by the authors and/or other copyright owners and it is a condition of accessing publications that users recognise and abide by the legal requirements associated with these rights.

- Users may download and print one copy of any publication from the public portal for the purpose of private study or research.

- You may not further distribute the material or use it for any profit-making activity or commercial gain

- You may freely distribute the URL identifying the publication in the public portal 


\title{
Accelerated Passive Dosing of Hydrophobic Complex Mixtures- Controlling the Level and Composition in Aquatic Tests
}

\author{
Rikke Hammershøj, Heidi Birch, Karina K Sjøholm, and Philipp Mayer*
}

Cite This: Environ. Sci. Technol. 2020, 54, 4974-4983

Read Online

ABSTRACT: Petroleum products and essential oils are complex mixtures of hydrophobic and volatile chemicals and are categorized as substances of unknown or variable composition, complex reaction products, or biological materials (UVCBs). In aquatic testing and research of such mixtures, it is challenging to establish initial concentrations without the addition of cosolvents, to maintain constant concentrations during the test, and to keep a constant mixture composition in dilution series and throughout test duration. Passive dosing was here designed to meet these challenges by maximizing the surface area $\left(A_{\text {donor }} / V_{\text {medium }}=3.8\right.$ $\left.\mathrm{cm}^{2} / \mathrm{mL}\right)$ and volume $\left(V_{\text {donor }} / V_{\text {medium }}>0.1 \mathrm{~L} / \mathrm{L}\right)$ of the passive dosing donor in order to ensure rapid mass transfer and avoid donor depletion for all mixture constituents. Cracked gas oil,

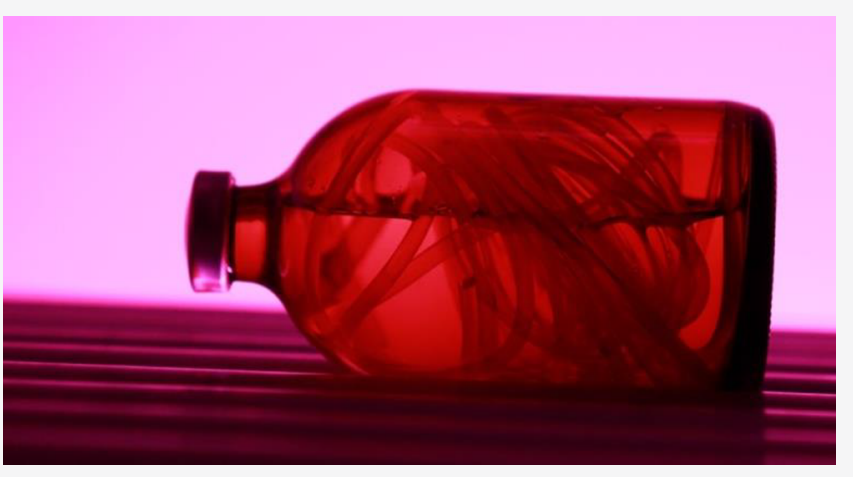
cedarwood Virginia oil, and lavender oil served as model mixtures. This study advances the field by (i) showing accelerated passive dosing kinetics for 68 cracked gas oil constituents with typical equilibration times of 5-10 min and for 21 cederwood Virginia oil constituents with typical equilibration times $<1 \mathrm{~h}$, (ii) demonstrating how to control mixture concentration and composition in aquatic tests, and (iii) discussing the fundamental differences between solvent spiking, water-accommodated fractions, and passive dosing.

\section{INTRODUCTION}

Concern about the risk related to the use and emissions of complex chemical mixtures has increased in recent years. ${ }^{1,2}$ These mixtures pose new challenges for experimental research and regulatory testing since they can contain hundreds or thousands of constituents with different physicochemical properties. This is especially true for complex mixtures of hydrophobic chemicals, such as petroleum products and essential oils, where a varying degree of water solubility, sorption, and evaporative losses for the hydrophobic constituents make it challenging to control and preserve the mixture level and composition in water. ${ }^{3-6} \mathrm{New}$ methods are therefore urgently needed to introduce hydrophobic complex mixtures into test systems to ensure exposure control during experiments and tests.

The most common way to introduce single hydrophobic organic chemicals (HOC) into aquatic tests is solvent spiking, where the test chemical is added with a cosolvent in order to set the nominal concentration. However, solvent spiking has several limitations and drawbacks. 5,7 The cosolvent can itself be toxic, modify the toxicity of the test chemical, or stimulate biomass growth, ${ }^{7,8}$ which requires keeping cosolvent concentration at an absolute minimum. When testing mixtures, a solvent can also give preferential dissolution of some mixture constituents, ${ }^{5}$ and the least water-soluble constituents may be spiked at concentrations above their solubility and then precipitate as the solvent mixes into the water. ${ }^{7,9}$

A common way to introduce complex mixtures of HOCs into aquatic tests is the water-accommodated fraction (WAF), 5,10 which has especially been used for petroleum products. To make a WAF, the mixture is directly added to the water and mixed for several hours or days. The WAF is then allowed to settle before the water fraction is used for further testing. The WAF is highly relevant for aquatic testing within an oil spill context, where it to some degree reflects the resulting mixture exposure in the aqueous phase. Concentration series can be made by varying the oil-loading rate of the WAF, reflecting different oil spill scenarios, which will result in treatments with different mixture composition. ${ }^{11}$ A potential issue is the formation of oil droplets in the test solution, which is often not desirable. Droplet formation can be minimized by using slow-stirring WAF methods ${ }^{10}$ that however require longer equilibration times.

Received: October 8, 2019

Revised: March 3, 2020

Accepted: March 6, 2020

Published: March 6, 2020

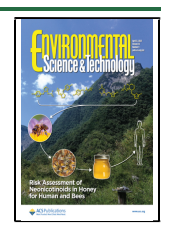


Table 1. Overview of Dosing Methods ${ }^{a}$

\begin{tabular}{|c|c|c|c|}
\hline & 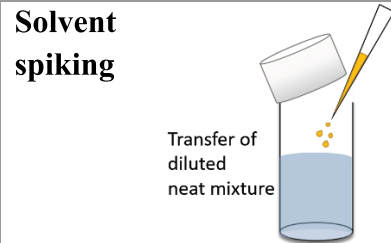 & $\begin{array}{l}\text { Water } \\
\text { accommodated } \\
\text { fraction }\end{array}$ & $\left.\begin{array}{l}\text { Loaded } \\
\text { silicone } \\
\text { donor }\end{array}\right\} \begin{array}{l}\text { Equilibrium } \\
\text { partitioning } \\
\text { between } \\
\text { donor and } \\
\text { water/air }\end{array}$ \\
\hline $\begin{array}{l}\text { Physicochemical } \\
\text { principle }\end{array}$ & $\begin{array}{l}\text { Nominal concentration is set } \\
\text { by quantitative transfer of } \\
\text { mixture: } \\
C_{\text {water,mix }}=m_{\text {mix }} / V_{\text {water }} \\
C_{\text {water, } i}=C_{\text {water,mix }} \cdot f_{i}\end{array}$ & $\begin{array}{l}\text { Partitioning and dissolution from } \\
\text { mixture to water, Raoult's law } \\
\text { regime }\end{array}$ & $\begin{array}{l}\text { Partitioning of each mixture constituent } \\
\text { from dominant donor to water. } \\
\text { Typically operated within Henry's law } \\
\text { regime (loading }<5 \mathrm{wt} \% \text { ): } \\
\qquad C_{\text {water, } i}=\frac{C_{\text {Silicone }, i}}{K_{\text {silicone,water }, i}} \\
\text { At very high donor loading, partitioning } \\
\text { according to Raoult's law. }\end{array}$ \\
\hline $\begin{array}{l}\text { Mixture } \\
\text { composition in } \\
\text { water }\end{array}$ & $\begin{array}{l}\text { Composition of mixture } \\
\text { transferred to water }\end{array}$ & $\begin{array}{l}\text { Composition modified by } \\
\text { partitioning, varies with } \\
\text { concentrations due to depletion }\end{array}$ & $\begin{array}{l}\text { Composition modified by partitioning. } \\
\text { Constant composition at varying con- } \\
\text { centration within Henry's law regime. }\end{array}$ \\
\hline $\begin{array}{l}\text { Replenishes losses } \\
\text { during testing }\end{array}$ & No & No & Yes \\
\hline $\begin{array}{l}\text { Avoiding co- } \\
\text { solvent addition }\end{array}$ & No & Yes & Yes \\
\hline $\begin{array}{l}\text { Condensation/ } \\
\text { precipitation of } \\
\text { pure phase }\end{array}$ & $\begin{array}{l}\text { Prone to precipitation of } \\
\text { least soluble constituents at } \\
\text { high concentration additions }\end{array}$ & $\begin{array}{l}\text { Common for high energy WAFs, } \\
\text { very limited for low energy WAFs }\end{array}$ & $\begin{array}{l}\text { Very limited, but can happen close to } \\
\text { saturation }\end{array}$ \\
\hline
\end{tabular}

${ }^{a} C_{\text {water,mix }}:$ mixture concentration in water. $m_{\text {mix }}:$ mixture mass. $V_{\text {water }}:$ water volume. $C_{\text {water } j i}$ : concentration of constituent $i$ in water. $f_{i}:$ fraction of constituent $i$ in the mixture. $C_{\text {silicone } s_{i}}$ : concentration of constituent $i$ in the silicone.

Lastly, passive dosing is increasingly used for setting and maintaining HOC exposure in aquatic tests. In passive dosing, a biocompatible polymer such as silicone is loaded with the test substance and then used as dominant partitioning donor to establish and control freely dissolved HOC concentrations in an aqueous medium. ${ }^{5,12-15}$ This approach has been used in many types of toxicity studies, ${ }^{13-19}$ bioaccumulation studies, ${ }^{20,21}$ biodegradation studies, ${ }^{22-27}$ and binding and sorption studies $^{28-31}$ and for solubility measurements. ${ }^{32,33}$ Passive dosing has so far primarily been used for research on single compounds and simple mixtures and more recently for research on defined composed mixtures of more than 30 chemicals. ${ }^{25}$ For complex mixtures, passive dosing has only been used to dose crude oil and fuel oil into water near the saturation limit. ${ }^{34-36}$ Table 1 provides a comparison of the three dosing methods (solvent spiking, WAF, and passive dosing) based on their underlying principles.

During passive dosing, each constituent, $i$, of a mixture partitions according to its own silicone to water partition coefficient, $K_{\text {silicone,water, } i}$. This partitioning is widely exploited within analytical chemistry, since it is well behaved and characterized by linear partitioning isotherms (i.e., constant partition coefficients) within a wide concentration range. ${ }^{37}$ The linear partitioning implies that a change in silicone loading level (concentration of each constituent in the silicone, $C_{\text {silicone }, i}$ ) will lead to a proportional change in aqueous concentrations $\left(C_{\mathrm{water}, i}\right)$ and an unchanged mixture composition (since $C_{\mathrm{water}, i}$ $\left.=C_{\text {silicone }, i} / K_{\text {silicone,water }, i}\right)$. While WAFs resemble oil spill scenarios, passive dosing is a partitioning system with similarities to exposure scenarios where the chemical mixture is $(\mathrm{ab})$ sorbed to a dominant organic phase from where it partitions into the water (e.g., polluted sediments or WWTP sludge).

For passive dosing of complex mixtures, the dosing kinetics should be maximized in order to ensure equilibrium partitioning of all constituents into the aqueous medium. These passive dosing kinetics depend on a range of factors but mainly on (1) the agitation level that sets the thickness of the aqueous boundary layer and (2) the ratio between the donor surface area and the volume of water $\left(A_{\text {Donor }} / V_{\text {Water }}\right){ }^{20,28}$ Passive dosing kinetics have mostly been enhanced by stirring or shaking (60$500 \mathrm{rpm}$ ), resulting in equilibrium times in the range of $1-48 \mathrm{~h}$ into ultrapure water. ${ }^{13,14,38,39}$ Shorter equilibrium times of $10-$ $20 \mathrm{~min}$ have been reported but were achieved by vigorous shaking at $1000 \mathrm{rpm}^{13,22,28}$ or at elevated temperature. ${ }^{40}$ For complex mixtures the fastest reported equilibrium time is 24 h. ${ }^{34,36}$ Passive dosing kinetics were in the present study accelerated by maximizing the $A_{\text {Donor }} / V_{\text {Water }}$ ratio ${ }^{20}$ while only gently agitating the systems by horizontal rolling. When dosing complex mixtures, it is also critical to ensure a large donor volume to water volume ratio $\left(V_{\text {Donor }} / V_{\text {Water }}\right)$ in order to avoid donor depletion, even for the least hydrophobic mixture constituents.

The first and primary aim of this study was to develop and optimize a passive dosing method for complex mixtures of HOCs to (i) control the concentration level and composition of the complex mixture, (ii) provide fast dosing kinetics for all mixture constituents, and (iii) maintain the mixture level and composition during an experiment. A large silicone donor was used to accelerate the dosing kinetics (high $A_{\text {Donor }} / V_{\text {Water }}$ ratio) and to avoid donor depletion (high $V_{\text {Donor }} / V_{\text {Water }}$ ratio). This 
optimized passive dosing approach was applied to a petroleum and an essential oil UVCB, targeting an independent control of mixture level and composition.

Passive dosing has been used in research for 20 years ${ }^{12}$ and was recently included in an OECD guidance document on aqueous-phase aquatic toxicity testing of difficult test chemicals for establishing and maintaining constant concentration against experimental losses. ${ }^{5}$ A second aim of this study was therefore to determine how evaporative losses affect the test exposure depending on the applied dosing method. This was explored using the same petroleum UVCB and a second essential oil UVCB.

\section{EXPERIMENTAL SECTION}

Test Chemicals and Materials. Three UVCB substances were included in this study: cracked gas oil (Concawe, Belgium), cedarwood Virginia oil (CAS: 8000-27-9/85085-41-2, Givaudan, UK), and lavender oil (CAS: 90063-37-9, Manske, Germany). The cracked gas oil was a distillate petroleum product consisting primarily of hydrocarbons with carbon numbers in the range from $\mathrm{C} 12$ to $\mathrm{C} 21$ and boiling points in the range of approximately $200-360{ }^{\circ} \mathrm{C}$. The cedarwood Virginia oil was a steam distillate made up of primarily sesquiterpene hydrocarbons and sesquiterpene alcohols with $\alpha$-cedrene, cedrol, and thujopsene being the main constituents. The lavender oil was a steam distillate having constituents such as monoterpene hydrocarbons, monoterpenoids, and acetate esters with linalool and linalyl acetate as the two major constituents. Translucent silicone rods (o.d. $3 \mathrm{~mm}$, polydimethylsiloxane, PDMS) without whitening agent were custom-made from Altec (UK) and used as partitioning donor in all experiments. Lowviscosity PDMS silicone oil (Sigma-Aldrich, Denmark) was used to make reference partitioning standards. Ethyl acetate ( $\geq 99.7 \%$ purity, Sigma-Aldrich) and ethanol (absolute, VWR International, Denmark) were used to clean the PDMS rods. Ultrapure water was produced with a LaboStar 1-DI ultrapure water system (SGwater, Germany).

Chemical Analysis and Data Processing. Automated headspace solid-phase microextraction (HS-SPME) was performed with a PAL RSI 85 autosampler (CTC Analytics, Switzerland) coupled to gas chromatography mass spectrometry (GC-MS) (7890B/5977A GC/MSD, Agilent Technologies, Denmark). An Agilent 122-5562 DB-5 ms Ultra Inert $60 \mathrm{~m} \times$ $0.25 \mathrm{~mm}, 0.25 \mu \mathrm{m}$ column was used for separation. A $7 \mu \mathrm{m}$ PDMS fiber was used for $60 \mathrm{~min}$ extraction at $35{ }^{\circ} \mathrm{C}$ at an agitation speed of $250 \mathrm{rpm}$. Details of the GC-MS program are described in Supporting Information 1. Autosampler vials with 5 $\mathrm{mL}$ of ultrapure water were included as blanks in each run. Reference partitioning standards with 0.5 wt \% test mixture in PDMS silicone oil were also included in each run. The reference partitioning standards were analyzed like all other samples and were used to check for potential changes in instrument sensitivity and retention time drifts. Reported peak heights for all constituents were within the linear range of detection. The automated HS-SPME-GC-MS method was found practical, sensitive, reproducible, and precise. However, it is important to note that the sensitivity of the GC-MS detector and the enrichment into the SPME fiber coating are constituent specific. This implies that these GC chromatograms are not faithful to the mixture composition in the aqueous phase. Comparisons of peaks across samples for specific chemicals are thus more meaningful than comparisons between chemicals/peaks within one chromatogram.
Full scan data files obtained with ChemStation (Agilent Technologies) were exported to MassHunter Unknown Analysis (Agilent technologies). Mixture constituents were found by deconvolution, and the base ion peak height of each analyte was used in further data analysis. ${ }^{41}$ Peak heights were used instead of peak areas since this reduces the error sustained in small changes in peak start and end, especially for small peaks. Details of the data processing are given in Supporting Information 1. Tentative identification based on comparison with the spectral library NIST of the 20 most dominant constituents in each test mixture are provided in Supporting Information 2.

Preparation and Loading of the Passive Dosing Systems. The passive dosing method used in this study is a further development of a method previously used to generate water for biodegradation testing of composed mixtures with up to 35 chemicals covering a wide chemical space in terms of $K_{a w}$ and $K_{\mathrm{ow}}{ }^{25}$ PDMS rods were used as passive dosing donor and were first rinsed with ultrapure water and dried twice with lintfree tissue to remove talcum. The rods were then totally immersed in ethyl acetate for $48 \mathrm{~h}$ to remove impurities and subsequently immersed twice in ethanol for $24 \mathrm{~h}$ to remove the ethyl acetate. Finally, they were rinsed twice with excess ultrapure water for $>12 \mathrm{~h}$ and dried in an oven at $120^{\circ} \mathrm{C}$ for $24 \mathrm{~h}$.

Loading was done by directly adding a defined volume of liquid chemical mixture to a cleaned PDMS rod in a glass jar using a gastight Hamilton syringe, followed by rolling for $48 \mathrm{~h}$ to allow the rod to absorb the mixture. The rod was then rolled with ultrapure water for $2 \mathrm{~h}$ before it was taken out, dried with lint-free tissues, and transferred to a clean bottle. The loaded rods were stored for up to 2 weeks and protected from contamination until use. The loading levels in the different experiments are listed in Supporting Information 3.

Silicone Loading Kinetics. Uptake (loading) kinetics and maximum uptake (i.e., swelling at saturation) in the PDMS rods were determined gravimetrically for each test mixture. Three 0.2 $\mathrm{g}$ silicone rods were placed in glass vials containing an excess amount of the liquid test mixture (full immersion). The weight increase of each rod was measured over $48 \mathrm{~h}$ by taking the rod out and wiping off excess mixture, reweighing it, and then placing it back into the liquid mixture. A simple kinetic model was fitted to the loading data (eq 1)

$$
C=C_{\mathrm{eq}}\left(1-\mathrm{e}^{-k t}\right)
$$

where $C(\mathrm{~g} / \mathrm{g})$ is the concentration of test mixture in the PDMS rod at time $t(\mathrm{~h}), C_{\mathrm{eq}}(\mathrm{g} / \mathrm{g})$ is the equilibrium concentration (which in this case is also saturation), and $k\left(\mathrm{~h}^{-1}\right)$ is the loading rate constant. Data were fitted by least-squares using GraphPad Prism v.8.1. The maximum swelling was determined for nine additional essential oils as part of a pretest for the passive dosing studies. These data are presented in Supporting Information 3.

Passive Dosing Kinetics. A $20.0 \mathrm{~g}$ silicone rod $(3 \mathrm{~mm}$ diameter, $\sim 2.6 \mathrm{~m}$ long) loaded with either $0.5 \mathrm{wt} \%$ cracked gas oil or cedarwood Virginia oil was placed in a $100 \mathrm{~mL}$ amber glass serum bottle, and $65 \mathrm{~mL}$ of ultrapure water was added. The high $A_{\text {Donor }} / V_{\text {Water }}$ ratio $\left(\sim 3.8 \mathrm{~cm}^{2}\right.$ donor surface area $/ \mathrm{mL}$ water $)$ was chosen to accelerate the passive dosing kinetics. The bottle was closed with a polytetrafluoroethylene (PTFE)-faced silicone septum and aluminum crimp seal and placed on a horizontal laboratory roller at $60 \mathrm{rpm}$ and $20^{\circ} \mathrm{C}$. After $3,5,10,20$, and 40 $\mathrm{min}, 5 \mathrm{~mL}$ of dosed water was sampled from the bottle using a gastight Hamilton syringe. The septum was briefly pierced with a 
needle after the $5,10,20$, and 40 min samples were taken to equalize pressure. After $2 \mathrm{~h}$, triplicate samples of $5 \mathrm{~mL}$ were taken from the bottle, and the remaining dosed water was discarded. All samples were transferred directly to $20 \mathrm{~mL}$ amber autosampler vials and analyzed within $24 \mathrm{~h}$. The procedure was repeated two additional times with the same passive dosing bottle to produce three passive dosing kinetic curves obtained with the same passive dosing system for each oil type.

The passive dosing kinetics of mixture constituents was determined based on relative increases in selected ion peak height over time (i.e., nontarget analysis). Selection of peaks was done as described under the data processing section. The samples from each replicate kinetic curve were analyzed together, and the peak heights were normalized by the average of the triplicate measurements at time $2 \mathrm{~h}$. This was done to correct for between day changes in instrument sensitivity, since a quantitative analysis method was used, and to ease the comparison between constituents. A simple model (eq 2) was fitted to the passive dosing kinetic data by least squares using GraphPad Prism v.8.1

$$
Y=Y_{\text {eq }}\left(1-\mathrm{e}^{-k t}\right)
$$

where $Y$ is the selected ion peak height of a constituent in the dosed water at time $t(\mathrm{~min}), Y_{\text {eq }}$ is the equilibrium peak height, and $k\left(\mathrm{~min}^{-1}\right)$ is the passive dosing rate constant. The time to reach $95 \%$ of equilibrium, $T_{95 \%}$, was calculated $\left(T_{95 \%} \sim 3 / k\right)$ from the fitted model. In the second dosing of cracked gas oil the 20 and 40 min samples were not measured due to a technical problem.

Varying the Exposure Level at Maintained Composition. The loading level of the silicone was varied to confirm that passive dosing of each constituent to water is proportional to its loading level in the silicone (i.e., within a linear partitioning regime). Silicone rods of $5.0 \mathrm{~g}$ each were loaded with cracked gas oil at $0.17,0.52$, and $1.6 \mathrm{wt} \%$ or with cedarwood Virginia oil at $0.19,0.57$, and $1.7 \mathrm{wt} \%$ in triplicate. The $5 \mathrm{~g}$ rods were placed in $20 \mathrm{~mL}$ autosampler vials, and $10.0 \mathrm{~mL}$ of ultrapure water was added to each vial. The high $V_{\text {Donor }} / V_{\text {Water }}$ ratio $(\sim 0.55 \mathrm{~mL}$ donor $/ \mathrm{mL}$ water) was used to avoid donor depletion for all mixture constituents. The vials were closed with gastight stainless-steel screw caps lined with PTFE/silicone septa and placed at $20 \mathrm{rpm}$ horizontal rolling for $4 \mathrm{~h}$. The passive dosing systems were then placed on the autosampler and analyzed by HS-SPME-GC-MS within $24 \mathrm{~h}$ without removing the rods.

The effect of changing the loading level of the PDMS rod was evaluated by comparing the selected ion peak height of individual constituents obtained by passive dosing at the three different loading levels with those in the reference partitioning standards analyzed along with the passive dosing systems (nontarget analysis). Only samples analyzed in the same sequence were compared.

Analytical Comparison of Four Dosing Methods. This experiment was made to compare the exposure obtained by (a) solvent spiking, (b) low loading passive dosing, (c) passive dosing loaded nearly to saturation, and (d) a wateraccommodated fraction (WAF). Cracked gas oil was again used as test mixture. Cedarwood Virginia oil was substituted by lavender oil since the lavender oil had a more diverse composition, which made a comparison between dosing methods more meaningful. Test solutions a-d were prepared as follows. (a) Solvent spiking: spiking solution was made by adding 100 $\mu \mathrm{L}$ of test mixture to $100 \mathrm{~mL}$ of methanol. A $50 \mu \mathrm{L}$ amount of this solution was spiked to $50 \mathrm{~mL}$ of ultrapure water and mixed thoroughly ( $\sim 1 \mathrm{mg}$ mixture/L water).

(b) Passive dosing at low loading: three $1.0 \mathrm{~g}$ silicone rods were loaded with liquid test mixture to reach a concentration of 1 wt \% mixture in the rod. Each rod was placed in a $20 \mathrm{~mL}$ amber glass vial closed with a screw cap with PTFE/silicone septum and equilibrated with 7 $\mathrm{mL}$ of water for $2 \mathrm{~h}$ at $20 \mathrm{rpm}$. The $A_{\text {Donor }} / V_{\text {Water }}$ ratio was $\sim 1.7 \mathrm{~cm}^{2} / \mathrm{mL}$, and the $V_{\text {Donor }} / V_{\text {Water }}$ ratio was $\sim 0.16 \mathrm{~mL} /$ $\mathrm{mL}$.

(c) Passive dosing at high loading: three $1.0 \mathrm{~g}$ silicone rods were loaded with test mixture at approximately $70 \%$ of the maximum loading determined in the loading kinetics and swelling experiment. Each rod was placed in a $20 \mathrm{~mL}$ amber glass vial closed with a PTFE/silicone septum cap and equilibrated with $7 \mathrm{~mL}$ of water for $2 \mathrm{~h}$ at $20 \mathrm{rpm}$.

(d) WAF: A WAF loading of $1 \mathrm{~g} / \mathrm{L}$ was achieved by adding $4 \mathrm{~g}$ of the test mixture to $4.0 \mathrm{~L}$ of ultrapure water in a $5 \mathrm{~L}$ precleaned aspirator bottle. The aspirator bottle was closed at the top with a glass stopper and contained a glass-coated magnetic stir bar. The bottle had a glass outlet at the bottom mounted with a Teflon-lined silicone tube, which was closed with a metal clamp. All joints were sealed with Teflon tape. The WAF was mixed at $200 \mathrm{rpm}$ (no visible vortex) for $24 \mathrm{~h}$ in the dark. After $24 \mathrm{~h}$, the first $0.5 \mathrm{~L}$ of the WAF was discarded and another $240 \mathrm{~mL}$ was collected in a $240 \mathrm{~mL}$ amber glass bottle and closed with a $\mathrm{PTFE} /$ silicone septum cap. The lavender oil WAF turned out to be unsaturated at $1 \mathrm{~g} / \mathrm{L}$ for some constituents and was therefore excluded from the results.

To test the stability of the solutions obtained by the different dosing methods over several days, a simple test was conducted based on the dimensions and the conditions of an algal growth inhibition test but without test organisms. ${ }^{42}$ For each of the four dosing methods, $20 \mathrm{~mL}$ vials holding $7 \mathrm{~mL}$ of test solution were horizontally shaken at $200 \mathrm{rpm}$ and $20^{\circ} \mathrm{C}$ for $72 \mathrm{~h}$. Some of the vials were sealed with PTFE/silicone septum caps ("closed"), and some were closed with PTFE/silicone septum caps with a 3 $\mathrm{mm}$ diameter perforation ("open"). The loaded silicone rods were left in the passive dosing test solutions during these $72 \mathrm{~h}$. The HS-SPME-GC-MS measurements were done at the beginning and the end of the incubations for all four ways of dosing; $5 \mathrm{~mL}$ of test solution from each dosing method was transferred to $20 \mathrm{~mL}$ amber autosampler vials containing $0.5 \mathrm{~mL}$ of $1 \%$ sodium azide in water and analyzed within $24 \mathrm{~h}$.

Estimation of Partition Coefficients and Mass Balance Calculations. The governing partition coefficients of representative constituents from each test mixture were calculated using the UFZ-LSER database ${ }^{43}$ and are shown in Tables S8S10. These partition coefficients apply to low and moderate concentration levels, where the partitioning is linear and follows Henry's law. WAFs and high-concentration passive dosing were operated at or near saturation, where the partitioning is expected to follow Raoult's law and where the estimated partition coefficients not necessarily apply.

The calculated partition coefficients were applied in simple mass balance calculations for water-air and water-air-silicone systems to illustrate the phase distribution of representative structures within these systems and to confirm that the silicone donor was dimensioned sufficiently large to ensure negligible- 
depletion passive dosing. Details and results are in Supporting Information 4.

\section{RESULTS AND DISCUSSION}

Silicone Loading Kinetics. Loading of the silicone rods by immersion in the liquid test mixtures was fast and reproducible (Figure 1), reaching 95\% of maximum swelling within $10 \mathrm{~h}$.

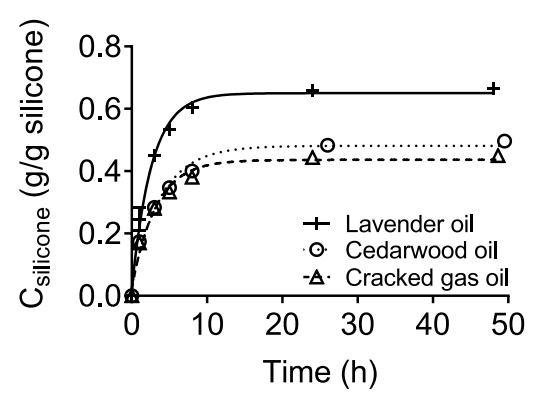

Figure 1. Loading kinetics determined by the mass of the test mixture in the silicone rod over time. $n=3$; mean \pm SEM.
Relative standard deviations were below $1 \%$ for triplicate loadings after $48 \mathrm{~h}$. The loading kinetics were very similar for the three test mixtures, while the maximum swelling differed. The rate-limiting step during loading is the diffusion of the chemicals within the silicone, and the thickness of the silicone is thus highly important. The equilibration time of $10 \mathrm{~h}$ found here for silicone rods with a diameter of $3 \mathrm{~mm}$ was consistent with equilibration times of $4.4 \mathrm{~h}$ for O-rings with a diameter of $2.4-2.6 \mathrm{~mm}$ and $<20 \mathrm{~h}$ for O-rings with a diameter of $5.3 \mathrm{~mm}$ immersed in $n$ dodecyl benzene. ${ }^{16}$ It also compares well with equilibrium times below $20 \mathrm{~h}$ reported for direct immersion of O-rings in crude oil. ${ }^{36}$ Loading of silicone with complex mixtures by direct immersion of the PDMS rods into the test mixture was thus simple and fast and had a high precision.

Passive Dosing Kinetics. Passive dosing kinetic curves were fitted for 68 individual constituents in cracked gas oil and 21 constituents in cedarwood Virginia oil (four representative kinetic curves are shown in Figure 2, all shown in Supporting Information 5). From these the time to obtain $95 \%$ of the equilibrium concentration for each constituent was calculated
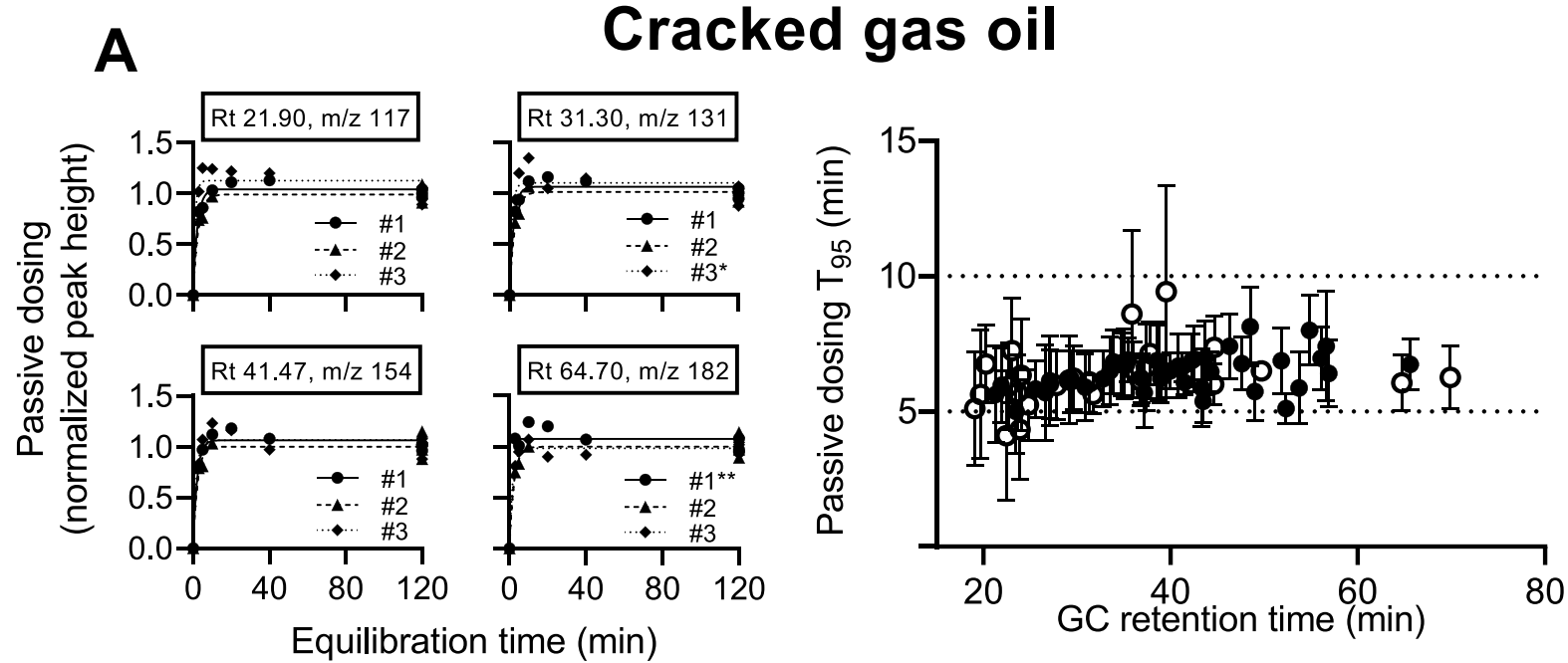

B
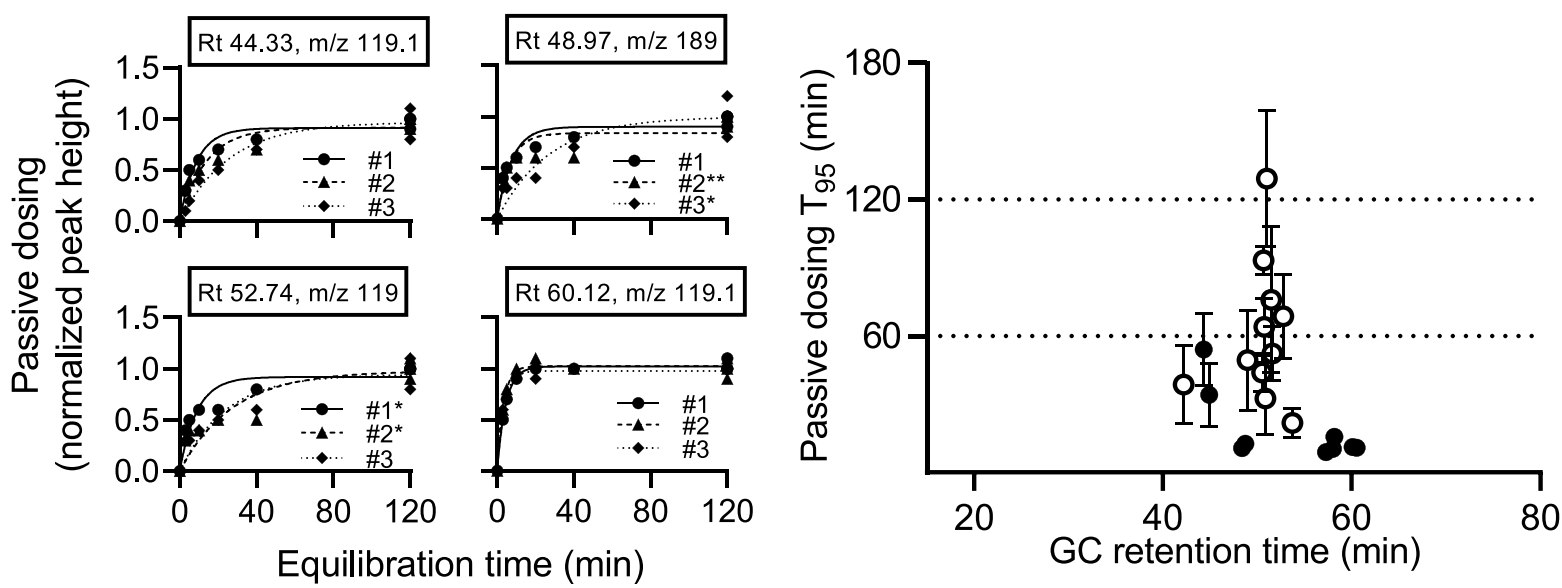

Figure 2. (Left) Passive dosing kinetic curves for four of the individual constituents in (A) cracked gas oil and (B) cedarwood Virginia oil in three replicate dosings. Model fit with $R^{2}>0.9$ unless otherwise noted: (*) fit with $0.8<R^{2}<0.9$; (**) ambiguous or poor fit $\left(R^{2}<0.8\right)$. (Right) Time to reach $95 \%$ of the equilibrium concentration for mixture constituents plotted against their GC retention times: $n=3$; mean \pm SEM; $R^{2}>0.9$. Open symbols indicate $T_{95}$ values that are based on fits either with $R^{2}$ between 0.8 and 0.9 or where $n=2$ since the last replicate had $R^{2}<0.8$. 
and plotted against the GC retention time (Rt), which was used as a surrogate for physical-chemical properties since it is available from the GC-MS analysis without compound identification (Figure 2).

For all constituents in cracked gas oil, the passive dosing was very fast, reaching $95 \%$ of equilibrium within $10 \mathrm{~min}$ (Figure $2 \mathrm{a}$ ), with an average $T_{95}$ of $6.3 \mathrm{~min}$. The model fits were generally good $\left(R^{2}>0.9\right)$, and for each mixture constituent the kinetics were similar in the three dosings (Figure 2a, Figure S3). The kinetics were also similar between constituents, and there was no trend with retention time.

For cedarwood Virginia oil, 95\% of equilibrium was reached within $\sim 1 \mathrm{~h}$ for most of the constituents (Figure $2 \mathrm{~b}$ ). One constituent was excluded because no good fit was obtained in two out of the three replicate dosings (Rt $45.66, m / z 119$, Figure S4). For about $30 \%$ of the cedarwood Virginia oil constituents the model fits were good $\left(R^{2}>0.9\right)$ and the kinetic curves similar for the three dosings and similar to curves found for cracked gas oil constituents. For about $70 \%$ of the cedarwood Virginia oil constituents, biphasic dosing kinetics were observed in at least one of the three dosings, with an initial rapid phase followed by a slower phase (e.g., constituents with Rt 48.97, $\mathrm{m} / z 189$, and Rt $52.74, m / z 119$, Figure $2 \mathrm{~b}$ ). The biphasic data resulted in poorer model fits (Figure S4) and longer apparent $T_{95}$, but there was no trend with retention time (Figure $2 \mathrm{~b}$ ) nor with water solubility and $\log K_{\text {ow }}$ (Figure S5).

In spite of imperfections for some cedarwood Virginia oil constituents, the passive dosing kinetics were overall very fast for constituents in both cracked gas oil and cedarwood Virginia oil with $T_{95}$ 's in the range from $10 \mathrm{~min}$ to no longer than $\sim 2 \mathrm{~h}$. This was obtained without rigorous shaking and at $20{ }^{\circ} \mathrm{C}$. The presented method is thus gentle enough to use in many toxicity and bioaccumulation studies. It can be upscaled to provide larger volumes of water to be used in for example biodegradation studies or even mesocosm studies as long as the $A_{\text {donor }} / V_{\text {water }}$ ratio is kept sufficiently high.

Varying Exposure Level at Maintained Composition. The performance of passive dosing for tightly controlling both the aqueous concentration level and the composition of complex mixtures was investigated by plotting peak heights of individual constituents at each concentration level against reference partitioning standards analyzed in the same sequence (Figure 3 ). The three silicone loading levels (factor 3 between mass loadings) were all below 2 wt $\%$ and thus within the Henry's law regime where linear partitioning applies.

For cracked gas oil the aqueous concentration level was precisely controlled between replicates and between the three passive dosing loading levels; the constituents were closely aligned along the perfect fit lines, showing that a change of a factor 3 in silicone loading level also led to a change of a factor 3 in aqueous concentration level for the individual constituents (Figure 3). The high precision of the passive dosing is indicated by the narrow range of vertical SEMs.

For cedarwood Virginia oil the concentration level was precisely controlled between replicates as illustrated by the narrow range of vertical SEMs but with higher variations at the highest concentration level. Nearly all constituents were located along or slightly above the perfect fit lines. For the two constituents having the highest peaks (Rt 44.33, $\mathrm{m} / z$ 119.1; Rt $45.66, m / z 119)$, the low-concentration points were located along the perfect fit line while the medium- and highconcentration points were higher than expected. Overall, the

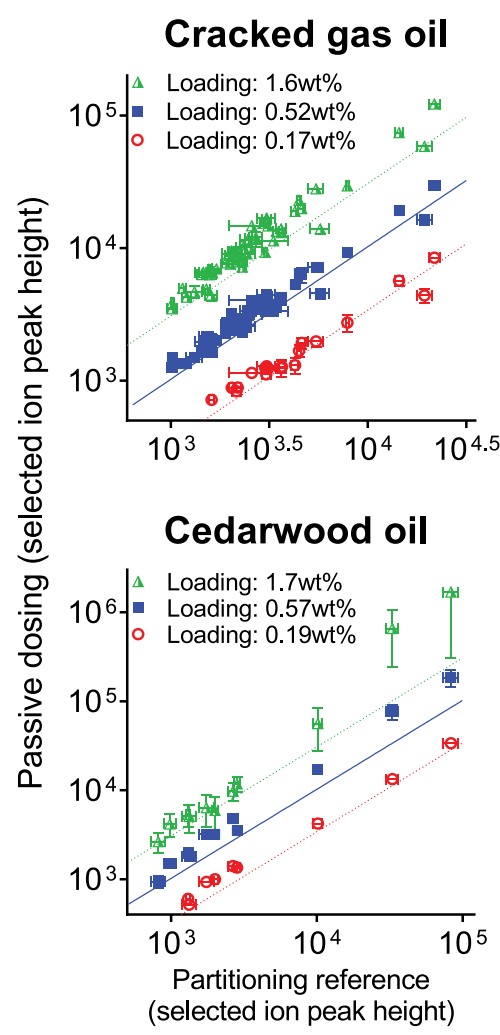

Figure 3. Peak height of constituents (53 in cracked gas oil, 11 in cedarwood Virginia oil) with GC retention times between 16 and 70 $\mathrm{min}$ at three different concentrations obtained by passive dosing plotted against peak heights in the reference partitioning standards. $n=3$; mean \pm SEM; lines are perfect fit lines ( $\mathrm{red}=1: 3$, blue $=1: 1$, and green $=3: 1$ ).

aqueous mixture composition of cedarwood Virginia oil was still maintained when changing the concentration level.

The data presented here show that passive dosing can be used to linearly change the aqueous concentration level of each mixture constituent by changing the silicone loading level, which also entails an overall preservation of the mixture composition. Passive dosing is thus suited to set mixture constituent concentrations at different levels in order to produce "dilutions" of the mixture in water while maintaining the mixture composition, as long as the silicone loading levels are within the Henry's law regime. Our experience with silicone-based analytical methods and passive dosing show that linear partitioning applies for $C_{\text {silicone }}<5 \%$ but can also extend to higher concentrations. ${ }^{42}$

Passive dosing can be used at concentrations above the linear partitioning range, but the relationship between silicone loading level and the resulting aqueous concentration and mixture composition is then less well defined. Near the saturation limit, passive dosing is again well defined and will behave according to Raoult's law ${ }^{44}$ just as water-accommodated fractions (WAF). However, that is not the primary focus of this study.

Comparison with Other Dosing Methods. Total ion chromatograms (TIC) were generated from full-scan MS of aqueous test solutions from four different dosing methods: (a) solvent spiking, (b) low-concentration passive dosing, (c) highconcentration passive dosing near the saturation limit, and (d) WAF (Figure 4 and Supporting Information 6).

Solvent Spiking. The chromatogram obtained by solvent spiking was markedly different from those obtained by passive dosing and WAF (Figure 4, Figure S11). This is because solvent 


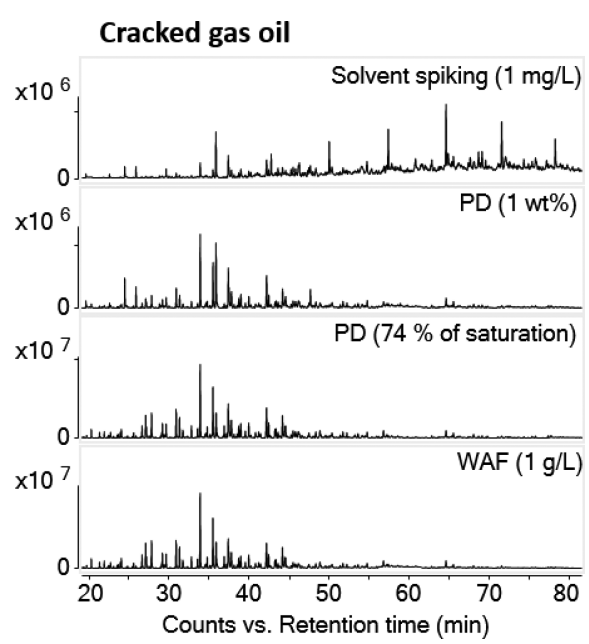

Figure 4. Total ion chromatograms (TICs) from HS-SPME-GC-MS analysis of aqueous samples obtained for cracked gas oil by different dosing methods: Solvent spiking, low-concentration passive dosing (PD), high-concentration PD, and a WAF. $n=1$. Peaks at a given retention time can be compared between chromatograms, whereas comparisons of peaks between retention times should be done with caution due to differences in SPME enrichment and MS sensitivity between mixture constituents.

spiking aims at a complete mass transfer of the entire mixture into the water, regardless of the hydrophobicity and solubility in water, and thus a conservation of the composition from neat mixture to spiked water. Passive dosing and WAF, on the other hand, are governed by partitioning processes and emphasize the less hydrophobic part of the mixture.

Low- vs High-Concentration Passive Dosing. Increasing the loading level of the silicone from 0.2 to $2 \mathrm{wt} \%$ resulted in a corresponding increase of aqueous concentration at an unchanged mixture composition (Figure 3). This observation was consistent with the working principle of passive dosing and our expectation of linear partitioning within the lowconcentration range where Henry's law applies. The chromatograms for cracked gas oil were generally also similar between low-concentration (0.01 g oil/g silicone, 1 wt \%) and high- concentration ( $0.35 \mathrm{~g}$ oil $/ \mathrm{g}$ silicone, $74 \%$ of saturation) passive dosing but with differences especially in the early part of the chromatogram (retention time 20-30 min; Figure 4). This indicates that the change in partitioning behavior with increased silicone loading level was similar for many but not all of the mixture constituents in cracked gas oil. For lavender oil the chromatograms obtained by passive dosing at low concentration $(0.01 \mathrm{~g}$ oil $/ \mathrm{g}$ silicone, $1 \mathrm{wt} \%)$ and high concentration $(0.43 \mathrm{~g}$ $\mathrm{oil} / \mathrm{g}$ silicone, $65 \%$ of saturation) were also fairly similar but with especially one constituent more prominent at the high level (Rt $32.5 \mathrm{~m} / z$ 69; Figure $\mathrm{S} 10)$.

High-Concentration Passive Dosing vs WAF. The cracked gas oil chromatograms from high-concentration passive dosing and WAF were very similar (Figure 4 and Figure S7). Passive dosing is a purely partitioning-based method, while WAFs are based on both partitioning and dissolution. However, close to saturation and with a sufficient amount of loaded silicone (passive dosing) or surplus of pure phase oil (WAF), both methods are fairly well described by Raoult's law. This explains the comparable mixture compositions obtained by the two methods. Similar findings have been reported in two other studies. $^{34,36}$

Buffering Losses during 3 Days Incubation. Three days of agitation resulted in different degrees of losses of cracked gas oil constituents in closed and open vials for the different test solutions (Figure 5; zoomed in to show details; full profiles in Supporting Information 6).

Nineteen representative constituents were selected within a retention time of $20-80 \mathrm{~min}$ and then used to calculate losses based on changes in the selected ion peak height. This semiquantitative analysis was only based on single replicates and does not represent the loss of the total mixture mass. Peak heights in closed vials on day 3 were on average within a factor of 2.4 of the day 0 levels for the WAF-dosed vial and both passive dosing vials. The loss in the closed cosolvent spiked vial was to the contrary a factor 8 , possibly because of higher sorptive losses at the lower concentration in this vial. High evaporative losses from the WAF and cosolvent spiked open vials after 3 days were indicated by average peak height ratios of 44 and 4.9, respectively, between the closed and the open vials. Passive
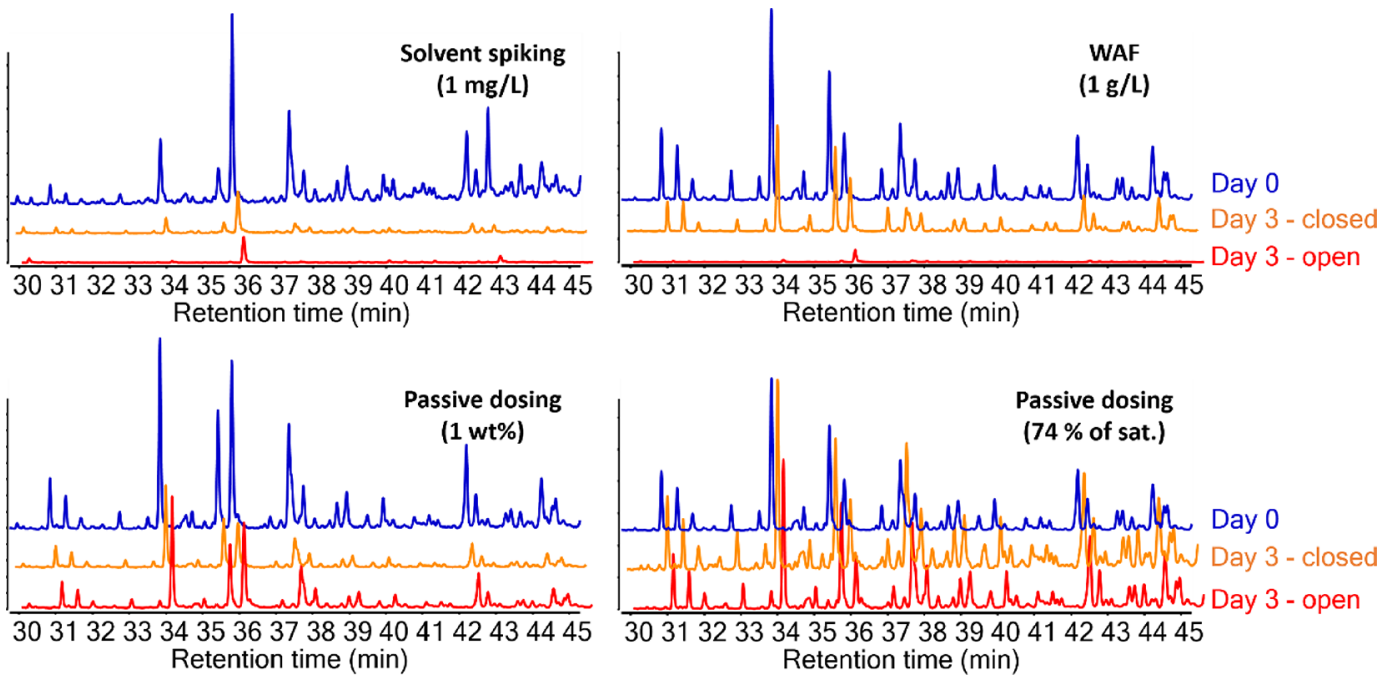

Figure 5. Section of TICs from HS-SPME-GC-MS analysis of cracked gas oil in water obtained by different dosing methods. Chromatograms were slightly shifted to facilitate visual comparisons. $x$ axis follows day 0 samples. Note that vertical scales are different for each dosing method (see Figure 4 and Supporting Information 6). $n=1$. 
dosing buffered these losses as indicated by the average peak height ratios between the closed and the open systems of 2.3 at the high-concentration level and of 1.0 at the low-concentration level. Hence, WAFs typically require working with sealed test systems and employ daily renewals, ${ }^{11}$ and the same is necessary when using solvent spiking. The ability of passive dosing to preserve mixture concentration and composition and the observed buffer capacity of the passive dosing donor was supported by estimated partition coefficients and mass balance calculations (Supporting Information 4). Passive dosing of complex mixtures can thus improve experimental designs by providing mechanisms for more stable aqueous exposures during testing.

Perspectives. The strategy to accelerate the passive dosing kinetics using a maximized $A_{\text {Donor }} / V_{\text {water }}$ ratio was highly successful. Equilibration times for cracked gas oil constituents were not only very short $(<10 \mathrm{~min})$ but also very similar between the constituents. The latter is consistent with previous passive dosing studies and with the assumption that diffusion through the unstirred boundary layer adjacent to the donor is rate limiting. ${ }^{28}$ The passive dosing kinetics of cederwood Virginia oil constituents were still rather fast, although they ranged from a few minutes to a few hours. Biphasic passive dosing kinetics were observed for several essential oil constituents. These observations might suggest a transition from one to another ratelimiting step and possibly also the presence and impact of additional abiotic processes. ${ }^{45}$ This calls for further research. The strategy to avoid donor depletion using a maximized $V_{\text {Donor }} /$ $V_{\text {water }}$ was also feasible and largely successful for all constituents included in the mass balance calculations. With a $V_{\text {Donor }} / V_{\text {water }}>$ $0.1 \mathrm{~L} / \mathrm{L}$, donor depletion can be kept minimal for all constituents with $K_{\text {silicone,water }}>100 \mathrm{~L} / \mathrm{L}$. To the contrary, UVCB constituents with $K_{\text {silicone,water }}<100 \mathrm{~L} / \mathrm{L}$ will be prone to donor depletion, which will lead to lowered aqueous concentrations and a reduced passive dosing buffer capacity.

The combination of accelerated passive dosing kinetics and large buffer capacity allows exposure levels to be varied at a constant mixture composition, which in turn can make mixture exposure a controlled instead of a dependent variable. However, the analytical methods to characterize and quantify UVCB exposure need further developments. The applied analytical method was sensitive and precise and provided quantification of known and unknown constituents, and it was highly suited for the aims of the present study. The next step should be a careful alignment of passive dosing and the applied analytics, where passive dosing provides exposure control whereas the analytical methods provide GC chromatograms that represent the aqueous mixture composition.

\section{ASSOCIATED CONTENT}

\section{SI Supporting Information}

The Supporting Information is available free of charge at https://pubs.acs.org/doi/10.1021/acs.est.9b06062.

GC-MS program details and data processing, tentative identification of mixture constituents, loading levels of PDMS rods and maximum swellings, phase distribution calculations, passive dosing kinetics, and comparison of compositions profiles for test solutions prepared with different methods (PDF)

\section{AUTHOR INFORMATION}

\section{Corresponding Author}

Philipp Mayer - Department of Environmental Engineering, Technical University of Denmark, 2800 Kongens Lyngby, Denmark; 이이.org/0000-0001-5138-7506; Email: philm@env.dtu.dk

\section{Authors}

Rikke Hammershøj - Department of Environmental Engineering, Technical University of Denmark, 2800 Kongens Lyngby, Denmark; 이이이.org/0000-0001-7422-7863

Heidi Birch - Department of Environmental Engineering, Technical University of Denmark, 2800 Kongens Lyngby, Denmark; 이이.orid.org/0000-0002-7152-3832

Karina K Sjøholm - Department of Environmental Engineering, Technical University of Denmark, 2800 Kongens Lyngby, Denmark

Complete contact information is available at:

https://pubs.acs.org/10.1021/acs.est.9b06062

\section{Notes}

The authors declare no competing financial interest.

\section{ACKNOWLEDGMENTS}

We are grateful to Hanne Bøggild for technical assistance in the laboratory, to Aaron Redman, Karen Jenner, Dan Salvito, Chris Hughes, and Eleni Vaiopoulou for their comments on the draft manuscript, and to three anonymous reviewers for helpful suggestions. This study was mainly funded by Concawe and the Research Institute for Fragrance Materials (RIFM). K.K.S., H.B., and P.M. acknowledge additional funding from CEFIC LRI (ECO 38, ECO 42).

\section{REFERENCES}

(1) Kortenkamp, A.; Faust, M. Regulate to Reduce Chemical Mixture Risk. Science 2018, 361 (6399), 224-226.

(2) Escher, B. I.; Stapleton, H. M.; Schymanski, E. L. Tracking Complex Mixtures of Chemicals in Our Changing Environment. Science (Washington, DC, U. S.) 2020, 367 (6476), 388-392.

(3) Schmidt, S. N.; Holmstrup, M.; Smith, K. E. C.; Mayer, P. Passive Dosing of Polycyclic Aromatic Hydrocarbon (PAH) Mixtures to Terrestrial Springtails: Linking Mixture Toxicity to Chemical Activities, Equilibrium Lipid Concentrations, and Toxic Units. Environ. Sci. Technol. 2013, 47 (13), 7020-7027.

(4) Jahnke, A.; Mayer, P.; Schäfer, S.; Witt, G.; Haase, N.; Escher, B. I. Strategies for Transferring Mixtures of Organic Contaminants from Aquatic Environments into Bioassays. Environ. Sci. Technol. 2016, 50 (11), 5424-5431.

(5) OECD. Guidance Document on Aquatic Toxicity Testing of Difficult Substances and Mixtures. OECD Series on Testing and Assessment No. 23, 2nd ed.; OECD, 2019; DOI: 10.1787/0ed2f88e-en.

(6) Birch, H.; Kramer, N.; Mayer, P. Time-Resolved Freely Dissolved Concentrations of Semi-Volatile and Hydrophobic Test Chemicals in In Vitro Assays - Measuring High Losses and Crossover by Headspace Solid-Phase Microextraction. Chem. Res. Toxicol. 2019, 32 (2), 17801790.

(7) Weyman, G. S.; Rufli, H.; Weltje, L.; Salinas, E. R.; Hamitou, M. Aquatic Toxicity Tests with Substances That Are Poorly Soluble in Water and Consequences for Environmental Risk Assessment. Environ. Toxicol. Chem. 2012, 31 (7), 1662-1669.

(8) Hutchinson, T. H.; Shillabeer, N.; Winter, M. J.; Pickford, D. B. Acute and Chronic Effects of Carrier Solvents in Aquatic Organisms: A Critical Review. Aquat. Toxicol. 2006, 76 (1), 69-92.

(9) Rojo-Nieto, E.; Smith, K. E. C.; Perales, J. A.; Mayer, P. Recreating the Seawater Mixture Composition of HOCs in Toxicity Tests with 
Artemia Franciscana by Passive Dosing. Aquat. Toxicol. 2012, 120, $27-$ 34.

(10) Singer, M. M.; Aurand, D.; Bragin, G. E.; Clark, J. R.; Coelho, G. M.; Sowby, M. L.; Tjeerdema, R. S. Standardization of the Preparation and Quantitation of Water-Accommodated Fractions of Petroleum for Toxicity Testing. Mar. Pollut. Bull. 2000, 40 (11), 1007-1016.

(11) Redman, A. D.; Parkerton, T. F. Guidance for Improving Comparability and Relevance of Oil Toxicity Tests. Mar. Pollut. Bull. 2015, 98 (1-2), 156-170.

(12) Mayer, P.; Wernsing, J.; Tolls, J.; De Maagd, P. G. J.; Sijm, D. T. H. M. Establishing and Controlling Dissolved Concentrations of Hydrophobic Organics by Partitioning from a Solid Phase. Environ. Sci. Technol. 1999, 33 (13), 2284-2290.

(13) Smith, K. E. C.; Dom, N.; Blust, R.; Mayer, P. Controlling and Maintaining Exposure of Hydrophobic Organic Compounds in Aquatic Toxicity Tests by Passive Dosing. Aquat. Toxicol. 2010, 98 (1), 15-24. (14) Smith, K. E. C.; Oostingh, G. J.; Mayer, P. Passive Dosing for Producing Defined and Constant Exposure of Hydrophobic Organic Compounds during in Vitro Toxicity Tests. Chem. Res. Toxicol. 2010, 23 (1), 55-65.

(15) Kiparissis, Y.; Akhtar, P.; Hodson, P. V.; Brown, R. S. PartitionControlled Delivery of Toxicants: A Novel in Vivo Approach for Embryo Toxicity Testing. Environ. Sci. Technol. 2003, 37 (10), 22622266.

(16) Stibany, F.; Schmidt, S. N.; Schäffer, A.; Mayer, P. Aquatic Toxicity Testing of Liquid Hydrophobic Chemicals - Passive Dosing Exactly at the Saturation Limit. Chemosphere 2017, 167, 551-558.

(17) Qi, H.; Li, H.; Wei, Y.; Mehler, W. T.; Zeng, E. Y.; You, J. EffectDirected Analysis of Toxicants in Sediment with Combined Passive Dosing and in Vivo Toxicity Testing. Environ. Sci. Technol. 2017, 51 (11), 6414-6421.

(18) Zhang, X.; Xia, X.; Li, H.; Zhu, B.; Dong, J. Bioavailability of Pyrene Associated with Suspended Sediment of Different Grain Sizes to Daphnia Magna as Investigated by Passive Dosing Devices. Environ. Sci. Technol. 2015, 49 (16), 10127-10135.

(19) Smith, K. E. C.; Schmidt, S. N.; Dom, N.; Blust, R.; Holmstrup, M.; Mayer, P. Baseline Toxic Mixtures of Non-Toxic Chemicals: "Solubility Addition" Increases Exposure for Solid Hydrophobic Chemicals. Environ. Sci. Technol. 2013, 47 (4), 2026-2033.

(20) Adolfsson-Erici, M.; Åkerman, G.; Jahnke, A.; Mayer, P.; McLachlan, M. S. A Flow-through Passive Dosing System for Continuously Supplying Aqueous Solutions of Hydrophobic Chemicals to Bioconcentration and Aquatic Toxicity Tests. Chemosphere 2012, 86 (6), 593-599.

(21) Castro, M.; Sobek, A.; Yuan, B.; Breitholtz, M. Bioaccumulation Potential of CPs in Aquatic Organisms: Uptake and Depuration in Daphnia Magna. Environ. Sci. Technol. 2019, 53 (16), 9533-9541.

(22) Smith, K. E. C.; Rein, A.; Trapp, S.; Mayer, P.; Karlson, U. G. Dynamic Passive Dosing for Studying the Biotransformation of Hydrophobic Organic Chemicals: Microbial Degradation as an Example. Environ. Sci. Technol. 2012, 46 (9), 4852-4860.

(23) Tejeda-Agredano, M. C.; Mayer, P.; Ortega-Calvo, J. J. The Effect of Humic Acids on Biodegradation of Polycyclic Aromatic Hydrocarbons Depends on the Exposure Regime. Environ. Pollut. 2014, $184,435-442$.

(24) Birch, H.; Andersen, H. R.; Comber, M.; Mayer, P. Biodegradation Testing of Chemicals with High Henry's Constants Separating Mass and Effective Concentration Reveals Higher Rate Constants. Chemosphere 2017, 174, 716-721.

(25) Birch, H.; Hammershøj, R.; Mayer, P. Determining Biodegradation Kinetics of Hydrocarbons at Low Concentrations: Covering 5 and 9 Orders of Magnitude of Kow and Kaw. Environ. Sci. Technol. 2018, 52 (4), 2143-2151.

(26) Hammershøj, R.; Birch, H.; Redman, A. D.; Mayer, P. Mixture Effects on Biodegradation Kinetics of Hydrocarbons in Surface Water: Increasing Concentrations Inhibited Degradation Whereas Multiple Substrates Did Not. Environ. Sci. Technol. 2019, 53 (6), 3087-3094.

(27) Needham, T. P.; Payne, R. B.; Sowers, K. R.; Ghosh, U. Kinetics of PCB Microbial Dechlorination Explained by Freely Dissolved
Concentration in Sediment Microcosms. Environ. Sci. Technol. 2019, 53 (13), 7432-7441.

(28) Gouliarmou, V.; Smith, K. E. C.; De Jonge, L. W.; Mayer, P. Measuring Binding and Speciation of Hydrophobic Organic Chemicals at Controlled Freely Dissolved Concentrations and without Phase Separation. Anal. Chem. 2012, 84 (3), 1601-1608.

(29) Birch, H.; Mayer, P.; Lützhøft, H. C. H.; Mikkelsen, P. S. Partitioning of Fluoranthene between Free and Bound Forms in Stormwater Runoff and Other Urban Discharges Using Passive Dosing. Water Res. 2012, 46 (18), 6002-6012.

(30) Bolinius, D. J.; Macleod, M.; Iadaresta, F.; Holmbäck, J.; Jahnke, A. Sorptive Capacities of Nonpolymeric Plant Lipids for Hydrophobic Chemicals Determined by Passive Dosing. Environ. Sci. Technol. 2019, 53 (3), $1278-1286$.

(31) Humel, S.; Schmidt, S. N.; Sumetzberger-Hasinger, M.; Mayer, P.; Loibner, A. P. Enhanced Accessibility of Polycyclic Aromatic Hydrocarbons (PAHs) and Heterocyclic PAHs in Industrially Contaminated Soil after Passive Dosing of a Competitive Sorbate. Environ. Sci. Technol. 2017, 51 (14), 8017-8026.

(32) Kwon, H. C.; Kwon, J. H. Measuring Aqueous Solubility in the Presence of Small Cosolvent Volume Fractions by Passive Dosing. Environ. Sci. Technol. 2012, 46 (22), 12550-12556.

(33) Birch, H.; Redman, A. D.; Letinski, D. J.; Lyon, D. Y.; Mayer, P. Determining the Water Solubility of Difficult-to-Test Substances: A Tutorial Review. Anal. Chim. Acta 2019, 1086, 16-28.

(34) Kang, H. J.; Lee, S. Y.; Roh, J. Y.; Yim, U. H.; Shim, W. J.; Kwon, J. H. Prediction of Ecotoxicity of Heavy Crude Oil: Contribution of Measured Components. Environ. Sci. Technol. 2014, 48 (5), 29622970.

(35) Redman, A. D.; Butler, J. D.; Letinski, D. J.; Parkerton, T. F. Investigating the Role of Dissolved and Droplet Oil in Aquatic Toxicity Using Dispersed and Passive Dosing Systems. Environ. Toxicol. Chem. 2017, 36 (4), 1020-1028.

(36) Bera, G.; Parkerton, T.; Redman, A.; Turner, N. R.; Renegar, D. A.; Sericano, J. L.; Knap, A. H. Passive Dosing Yields Comparable Dissolved Aqueous Exposures of Crude Oil as CROSERF Water Accommodated Fraction Method. Environ. Toxicol. Chem. 2018, 37 (11), 2810-2819.

(37) Seethapathy, S.; Górecki, T. Applications of Polydimethylsiloxane in Analytical Chemistry: A Review. Anal. Chim. Acta 2012, 750, $48-62$.

(38) Smith, K. E. C.; Heringa, M. B.; Uytewaal, M.; Mayer, P. The Dosing Determines Mutagenicity of Hydrophobic Compounds in the Ames II Assay with Metabolic Transformation: Passive Dosing versus Solvent Spiking. Mutat. Res., Genet. Toxicol. Environ. Mutagen. 2013, $750(1-2), 12-18$.

(39) Van Der Heijden, S. A.; Hermens, J. L. M.; Sinnige, T. L.; Mayer, P.; Gilbert, D.; Jonker, M. T. O. Determining High-Quality Critical Body Residues for Multiple Species and Chemicals by Applying Improved Experimental Design and Data Interpretation Concepts. Environ. Sci. Technol. 2015, 49 (3), 1879-1887.

(40) Bougeard, C.; Gallampois, C.; Brack, W. Passive Dosing: An Approach to Control Mutagen Exposure in the Ames Fluctuation Test. Chemosphere 2011, 83 (4), 409-414.

(41) Sjøholm, K. K.; Flyckt-Nielsen, M.; Bucheli, T. D.; Mayer, P. Thermodynamic Assessment of (Semi-)Volatile Hydrophobic Organic Chemicals in WWTP Sludge - Combining Solid Phase Microextraction with Non-Target GC/MS. Environ. Sci. Process. Impacts 2018, 20 (12), $1728-1735$.

(42) Trac, L. N.; Schmidt, S. N.; Holmstrup, M.; Mayer, P. Headspace Passive Dosing of Volatile Hydrophobic Organic Chemicals from a Lipid Donor-Linking Their Toxicity to Well-Defined Exposure for an Improved Risk Assessment. Environ. Sci. Technol. 2019, 53 (22), 13468-13476.

(43) Helmholz Centre for Environmental Research-UFZ. UFZ-LSER Database: https://www.ufz.de/index.php?en $=31698 \&$ contentonly= $1 \& \mathrm{~m}=0 \& 1$ serd_data[mvc] $=$ Public/start (accessed 2019-08-05). 
(44) Atkins, P. W. Changes of State: Physical Transformations of Simple Mixtures. Physical Chemistry; Oxford University Press, 1990; pp 154-186.

(45) Turek, C.; Stintzing, F. C. Stability of Essential Oils: A Review. Compr. Rev. Food Sci. Food Saf. 2013, 12 (1), 40-53. 